\title{
Barriers and facilitators of the effectiveness of the clinical pedagogical supervision of nursing and obstetric students in sub-Saharan Africa: A systematic review
}

\author{
TASSEMBEDO Talato*, NGANGUE Patrice, Arzouma Hermann PILABRE, PAFADNAM Yacouba,, KINDA Abel \\ Téwendé, BARRO Abibata, TRAORE Doulaye, BATIONO Nestor, SOUBEIGA Dieudonné \\ Institut de Formation et de Recherche Interdisciplinaires en Sciences de la Santé et de l'Éducation (IFRISSE), Burkina Faso
}

Received: November 23, 2021

DOI: $10.5430 /$ jnep.v12n6p35
Accepted: February 14, 2022

Online Published: February 25, 2022

\begin{abstract}
Objective: Education in nursing and obstetrics combines theoretical learning with clinical experience. Thus, the internship organization and the supervision of a trainee require the cooperation of different partners in educational and health institutions that receive the trainees. This systematic review aimed to identify factors that facilitate or hinder the effectiveness of clinical educational supervision of nursing and obstetrics students.

Methods: Three electronic databases (PubMeb, CINAHL and ERIC) were searched. Two independent reviewers selected eligible publications based on inclusion and exclusion criteria. Qualitative, quantitative or mixed studies conducted in Sub-Saharan Africa and published between January 2011 and December 2020 were included.

Results: The study revealed that while there are some strengths (facilitators), clinical pedagogical supervision presents mostly weaknesses (barriers) at the structural and procedural levels. Of the 65 factors studied, all nine studies were unanimous that 54 were barriers and 3 were facilitators. In addition, eight factors were cited as both barriers and facilitators.

Conclusions: Clinical pedagogical supervision of nursing and midwifery students in sub-Saharan Africa faces major challenges of diverse origins that may undermine its effectiveness. It would be appropriate at the country level to analyze the barriers inherent in this supervision's structure and process and improve them.
\end{abstract}

Key Words: Barriers, Facilitators, Clinical educational supervision, Nursing, Obstetrics, Sub-Saharan Africa

\section{INTRODUCTION}

Nursing and obstetrics education is a sandwich course. It combines theoretical learning and clinical experience. ${ }^{[1-4]}$ Therefore, clinical placement is crucial for health care students in their training. ${ }^{[5]}$ In fact, in nursing and midwifery training, the internship is a pedagogical strategy that allows the student to see how the fundamentals of the nursing profession are integrated into the technical and organizational work of daily life and apply them to care. It also allows for learning by model, grasping the ethical, relational and organizational implications of the nurse's work, fostering professional identity development and facing the challenge of caring for the sick. ${ }^{[6]}$

Furthermore, the organization of the internship and the supervision of a student intern require the cooperation of various

*Correspondence: TASSEMBEDO Talato; Email: itassembed@yahoo.fr; Address: 09 BP 311 Ouagadougou 09, Ouagadougou, Burkina Faso. 
partners in the educational and health institutions that receive the interns. ${ }^{[7,8]}$ Thus, the clinical or clinical learning environment is critical in nursing students. ${ }^{[9]}$ Indeed, it is the clinical classroom with a complex social climate in which students, nurses, midwives, teachers and patients interact. ${ }^{[10]}$ Flott and Linden ${ }^{[11]}$ explain that the concept of a clinical learning environment encompasses four attributes that influence students' learning experiences: physical space, psychosocial factors and interactions, organizational culture, and elements of the teaching and learning process.

Supervision is the pedagogical action aimed at organizing an internship, directing and accompanying a trainee best to ensure the learning of his future function. It is a system of practical training and monitoring of students on placement. It is a support system whereby experienced health professionals trained in teaching in a clinical environment help trainees individually or in small groups develop the best practices (skills) to prepare them for their future profession. The aim is to achieve quality clinical care outcomes sustainably. ${ }^{[12,13]}$

However, internship difficulties remain even in countries where nursing and midwifery training is well implemented. The supervision of students is a real challenge, as internship sites do not meet the required quality conditions. ${ }^{[14,15]}$ Many countries have seen a cessation or decrease in the participation of clinical instructors due to organizational constraints associated with an increase in faculty workload. Workplaces are unstructured learning environments that offer varied and inconsistent learning opportunities. ${ }^{[16]}$ There is a recurrent difficulty for supervisors in Belgium to accompany their trainees. They lack the training and experience to manage the accompaniment professionally and are not prepared for this task. ${ }^{[17]}$ An exploration of undergraduate nursing students' perspectives on their clinical learning environment in Malawi revealed that the participants were not satisfied with clinical supervision and support during clinical learning. ${ }^{[18]}$ In Benin, a study of internship supervisors' perceptions of the management process and the quality of nursing and obstetrics supervision also revealed shortcomings in clinical teaching supervision. ${ }^{[19]}$ Recent studies in Africa have also reported that supervision is not carried out according to standards: ${ }^{[12,20-24]}$ see Appendix 1: Schematic representation of the study's framework (structure, process, and outcome variables). In short, the environment in which nurses and midwives learn clinical practice faces a multitude of factors that can impede learning. ${ }^{[25]}$ This is likely to result in inadequate patient care. ${ }^{[13]}$

However, this does not preclude the existence of positive (facilitating) aspects of clinical supervision of nursing and midwifery students. For example, studies have reported sat- isfactory availability of clinical staff and/or instructors. ${ }^{[25,26]}$ Others have even reported that supervisors demonstrate good clinical teaching skills. ${ }^{[1,2,9,14,27]}$

In sum, the above attests to a bivalent situation of the quality of clinical supervision. In this context, it is important to identify the strengths and weaknesses inherent in the educational process implemented during the internship to support the trainees in acquiring professional skills. ${ }^{[28]}$ This study is carried out within this scope.

Thus, we asked the following research question: What are the barriers and facilitators of the effectiveness of the clinical pedagogical supervision in nursing and midwifery sciences in sub-Saharan Africa?

\section{Methodology}

This systematic review examines the barriers and facilitators of the effectiveness of the clinical pedagogical supervision of nursing and obstetric students in sub-Saharan Africa. Clinical pedagogical supervision effectiveness determinants are twofold: structural and procedural. ${ }^{[29,30]}$ From this point of view, some studies are oriented towards the structure and or the process. Therefore, this study was conducted following the « Preferred Reporting Items for Systematic Reviews and Meta-Analyses » (PRISMA). ${ }^{[31]}$

\subsection{Research strategy}

A complete search strategy was developed to identify studies published between January 2011 and December 2020. Three electronic databases were consulted (PubMed, ERIC and CINAHL), combining terms related to clinical pedagogical supervision, nursing and obstetrics, teaching structures, clinical placement supervisors, midwifery and nursing students. Additional searches were done in Google scholar for exhaustiveness. The retrieved references were imported into Zotero. We conducted the searches in our databases from October 12 to October 31, 2020. An update was made on December 28, 2020. Detailed search strategies are available in Appendix 2.

\subsection{Selection of studies}

The initial search yielded 2018 studies. All identified records $(n=2018)$ were initially reviewed by two independent researchers and verified by a third researcher. PICOS (Population, Intervention, Control, Outcome, Study) criteria items were used as the basis for selecting studies. Thus, eligible studies had to meet the following criteria: (1) be an original research study; (2) be written in English or French; reporting: (3) nursing and obstetrics students; (4) nursing and obstetrics clinical placement supervisors; (5) clinical supervision; (6) clinical coaching; (7) clinical simulation; (8) clinical supervision infrastructure, instruments, materials, and tools; and 
(9) preparation, conduct, or evaluation of clinical coaching.

The study designs of interest were qualitative, quantitative, or mixed-method. In terms of geographical restriction, only studies in sub-Saharan Africa and published as scientific articles are included. Examination of the titles and abstracts of the articles allowed for excluding articles that were not relevant according to the pre-established criteria. Subsequently, two investigators compiled a shortlist of papers, and the full text was reviewed independently. Unrelated studies were excluded. The characteristics of the excluded studies are available in appendix 2. Uncertainties and disagreements about inclusion were resolved by discussion involving the two investigators. The flow chart illustrates the selection process in Appendix 3.

\subsection{Data extraction}

Two investigators independently extracted data from each study that met the inclusion criteria by using a standard form. Discrepancies were resolved by consensus. Data extracted included study characteristics such as first author, year of publication, the country in which the study was conducted, study purpose, study population and sample, study site, study design, data collection methods and tools, and outcomes associated with the effectiveness of the clinical pedagogical supervision analyzed in the study.

\subsection{Quality assessment}

The methodological quality of the selected articles was analyzed by two researchers, including the principal investigator, separately. The team members discussed discrepancies until a consensus was reached on the included studies. The analysis was done using different analysis grids depending on the study design. The Mixed Methods Appraisal Tool (MMAT) french version 2018 was used to assess methodological quality. ${ }^{[32]}$

\subsection{Data analysis}

Factors associated with the effectiveness of clinical educational coaching can be organized into barriers and facilitators based on the Donabedian quality model. This framework examines the multiple effects and interdependence of the environment (structural) and process on the effectiveness of clinical pedagogical supervision's product (outcome). We proceeded with a narrative synthesis of the data extracted from the articles, focusing on the description, interpretation and discussion of the barriers and facilitators of pedagogical supervision according to the Donabedian quality model, which we adapted (see Appendix 1) following Otti et al.'s ${ }^{[30]}$ tool for analyzing the quality of nursing supervision.

\section{RESULT}

\subsection{Study selection}

The primary search strategy identified 2018 potentially relevant studies. After initial screening by abstract titles, 13 studies were selected for full-text review. At this stage, four studies were excluded because they did not report results related to factors (structural and/or procedural) associated with the effectiveness of clinical pedagogical supervision (see Appendix 4). The remaining nine studies were assessed for methodological quality. No study was excluded based on quality assessment. The flow chart illustrating the selection process is shown in Appendix 3.

\subsection{Characteristics of the studies}

Appendix 5 provides a brief overview of the main characteristics of the included studies. Of the nine studies included, three were qualitative, and six were mixed-methods studies. All studies were conducted in sub-Saharan Africa, including 5 in South Africa (3 in Malawi and 2 in the Republic of South Africa), 2 in West Africa (Benin), 1 in East Africa (Uganda), and 1 in Central Africa (Cameroon). Two studies were French and seven in English. The study frequencies by population studied were: students $(n=5)$ including thirdyear $(n=1)$, first, second, and third-year $(n=1)$, the second year $(n=1)$, third and fourth year $(n=1)$, second and fourth year $(n=1)$; and supervisors $(n=4)$ including clinical staff $(\mathrm{n}=2)$, clinical staff, and teacher educators/practicum site referent $(\mathrm{n}=2)$.

The total sample size for all included studies was 1357 , consisting of 1138 students (252 nursing and midwifery students and 886 nursing students) and 219 supervisors (147 nursing and midwifery educators and 72 nursing educators).

Results from each study focused on structural and procedural aspects of clinical supervision. Barriers and facilitators are classified in these different results according to the structure and process of clinical pedagogical supervision (results column in Appendix 6).

\subsection{Quality assessment}

The studies were generally of high quality. Responses obtained by consensus to all methodological quality criteria according to the MMAT were "Yes" for each of the nine included studies (see Appendix 7).

\subsection{Barriers and facilitators of the effectiveness of the clinical pedagogical supervision of nursing and ob- stetric students}

In total, 65 factors associated with the effectiveness of clinical teaching supervision were identified. Of these factors, 54 were cited only as barriers and three as facilitators. The 
remaining eight were cited as both barriers and facilitators.

At the structural level, the factors were classified according to whether they concern the training institutions $(n=3)$, the internship sites $(n=11)$ and the two institutions at the same time $(n=6$. Thus, a total of 20 factors were reported. At the procedural level, 45 factors were cited. The factors were classified according to the preparation of the clinical internship $(n=15)$, the reception and integration of interns in a clinical setting $(n=9)$ and the internship course $(n=21)$.

When linking the categories, the factors can act as barriers to clinical teaching supervision and facilitators. Depending on what form they take in each study, some factors may be one or the other, or both.

We present the results according to the factors by level, indicating the number (n) and the studies that cited it as a barrier or facilitator. This is followed by Appendix 8 presenting respectively:

-distribution of studies by barriers and facilitators of clinical pedagogical supervision identified according to the factors; -according to level, group of factors defined in terms of weaknesses (barriers) and strengths (facilitators) of clinical pedagogical supervision.

\subsubsection{At the structural level}

The factors were grouped to educational institutions and internship sites or only to one.

\section{1) At the level of educational institutions and internship sites}

Three studies ${ }^{[19,33,34]}$ looked at and identified only the barriers that are the lack of: "Internship policies and standards for supervision of interns", $[33,34]$ "Partnership convention or affiliation contract between the training institution and the internship environment", ${ }^{[19]}$ "Internship convention between the training institution, the trainee and the internship sites", $[19,33]$ "Reception and clinical supervision charter elaborated in partnership between the training institution, the trainee and the internship environment", [19] "Student competency referential" [34] et al. "Standard and validated coaching and learning tools". ${ }^{[19,34]}$

\section{2) At the level of educational institutions}

Of the barriers, "students vocation and willingness" was most cited $(n=3)^{[19,35,36]}$ and "the existence of a clinical department with staff" once. ${ }^{[34]}$ In addition, the "interest of teachers in the internship" was cited both as a barrier ${ }^{[33]}$ and facilitator. $^{[37]}$

\section{3) At the level of the clinical internship sites}

All nine studies identified barriers from the results, and two ${ }^{[19,33]}$ identified facilitators. The details of these results are as follows.

\section{a) About infrastructures, materials and tools}

Regarding reported barrier factors, "the existence of a nursing staff room in each internship department for exchange and analysis of professional practices" was cited in 2 studies $^{[12,34]}$ and "the existence of sufficient clinical supervision materials (equipment and instruments) for the organization of learning situations for the benefit of trainees" in 8 studies. ${ }^{[12,18,19,33-35,37,38]}$ A facilitating factor, "the existence of practical guides for supervision," was mentioned in one study. ${ }^{[19]}$

\section{b) About the staff}

The nine included studies investigated factors associated with the characteristics of internship site personnel. From the findings, 4 barrier factors were identified across studies as follows: "for each internship environment, existence of supervision actors (of masters, tutors, internship proximity professionals) known in terms of roles, responsibilities and mission",[19,33,36,37] ( $n=4)$; "presence of qualified and competent internship supervisors (human, pedagogical, tech-

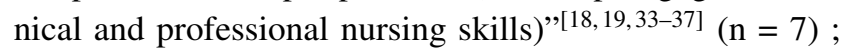
"availability of supervisors (number of staff)",[18,33,35] ( $\mathrm{n}=$ 4) and "motivation of the health care team to supervise students" $[12,18,33,35,37,38](n=6)$. In addition, the "presence of qualified health professionals concerning the disciplines practised" was reported as both a barrier ${ }^{[12,18,19,37]}(\mathrm{n}=4)$ and facilitator $^{[33]}(\mathrm{n}=1)$.

c) About the clinical cases and the services' professional activities packet

Three studies reported three factors. First, of the findings, "client/patient numbers" was cited as both a barrier ${ }^{[12,18]}$ $(n=2)$ and facilitator ${ }^{[33]}(n=1)$; "the existence of professional activities in the department allowing real learning for the student to achieve the internship objectives" as a barrier only ${ }^{[33]}(n=1)$ and "pathologies most encountered in the internship environment related to internship objectives" as a facilitator $^{[33]}(n=1)$.

\subsubsection{At the process level}

Factors (results) were classified according to the stages of pedagogical supervision: internship preparation, reception and integration of the interns in the clinical environment, and the internship course.

\section{1) About the preparation of the clinical internship}

All included studies $(n=9)$ reported 15 factors related to internship preparation. One factor, "providing students with internship tools", was reported as a facilitator ${ }^{[12]}(\mathrm{n}=1)$. Other factors were perceived only as barriers across studies as follows: "selection of internship sites and respect 
of criteria for choosing students to be assigned to an internship environment" ${ }^{12,18,19,33-35,37,38]}(\mathrm{n}=8)$; "the provision of sufficient clinical supervision materials (equipment and instruments) to the internship environments for the organization of learning situations for the benefit of interns" $[19,38](n=2)$; "educational training in the clinical pedagogical supervision approach for those involved in supervision"[35] $(\mathrm{n}=1)$, "the organization of clinical simulations in educational institutes/assimilation of techniques involvement of supervisors" $[12,19,34,35,38](n=5)$, "the number of trainees per site" $[18,35,36](n=3)$ «"the length of the internship" "[12, 19,34,35,37,38] ( $=6)$; "the moment (of the day) in which the internship takes place"[12] $(n=1)$; "the internship period" ${ }^{19,37]}(\mathrm{n}=2)$; "Explanation of the internship objectives to the interns, explanation of the internship process and informations about the internship environment" ${ }^{\text {"[12,35] }}(\mathrm{n}=$ $2)$; «the explanation of the course tools » ${ }^{[12]}(n=1)$; "The preparation of the clinical internship by the student himself (acquisition of equipment, health coverage)"[12,35] $(\mathrm{n}=2)$ "the realization of the preparatory meeting of the clinical supervision with the different actors in each department by the internship master" ${ }^{[12,19]}(\mathrm{n}=2)$.

2) About the reception and integration of interns in the clinical environment

A total of 9 factors for the reception and integration of trainees in the clinical environment were reported by five studies. ${ }^{[12,18,19,36,37]}$ Of these factors, "organizational reception of students by the internship master" was cited as both a barrier $^{[36]}(n=1)$ and facilitator ${ }^{[12]}(n=1)$. The other factors constituted barriers, namely:"the accompaniment of students by the educational institution's teacher (internship site referent)" $\left.{ }^{\text {" }} 12,18,37\right](n=3)$, "the presentation of the service staff to the students" ${ }^{[12]}(\mathrm{n}=1)$, "the presentation of the students to the staff", "the presentation of the organization and functioning of the service to students" and "the pedagogical reception of the students by the internship tutor"[12,36] (n=2), "the Rereading and clarification of internship objectives", "the presentation of the criteria and evaluation modalities of the internship" and "the presentation of the practical modalities of the internship" $[12,19,36](n=3)$.

\section{3) About the conduct of the course}

This stage consists of two points: clinical teaching and evaluation/regulation of the internship.

\section{a) On clinical teaching}

At this level, 18 factors were identified. One study ${ }^{[33]}$ did not cite a factor. The factors are related to "application of clinical supervision skills by supervisors" and "student behaviors".

\section{Application of clinical supervision skills by supervisors}

Factors related to managerial, clinical/technical and human/relational skills were cited only as barriers:

- managerial skills: "the organization of learning activities"[12,33,36,37] $(n=4)$,

- clinical/technical skills: "the expression of expertise in

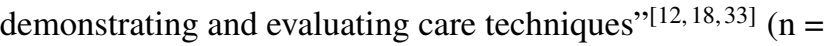
3),

- human or relational skills: "the establishment of a climate of trust" $[12,33,36,37](n=4)$, "the manifestation of an empathetic attitude" $[12,33,36](n=3)$ the use of personal quali$\operatorname{ties}^{[12,33,36,37]}(\mathrm{n}=4)$.

Factors related to pedagogical and didactic skills were cited as both barriers to "the assessment of students' needs and skills" $[12,18,33,37](n=4)$ and facilitator "the respect of the internship objectives". ${ }^{[33]}(\mathrm{n}=1)$.

\section{Student behavior}

Some factors were mentioned only as barriers, such as: "the questioning"[19] $(\mathrm{n}=2)$, "the assiduity to the internship" and "the respect and assistance to other students" ${ }^{[19]}(\mathrm{n}=1)$, "the punctuality at the internship" $[19,35](n=2)$, "the Respect for the supervisors" and "the respect of the organization and course of the internship" $[19,35,36,38](n=4)$.

The other factors were defined as both barrier and facilitator as follows:

- "the interest in the internship": barrier ${ }^{[19,35,38]}(\mathrm{n}=3)$, facilitator $^{[12]}(\mathrm{n}=1)$; - "the integration of a constructive learning approach": barrier $^{[19,38]}(n=2)$, facilitator ${ }^{[18]}(n=1)$ and - "the respect and assistance to other students": barrier ${ }^{[19]}$ (n $=1)$, facilitator ${ }^{[18]}(\mathrm{n}=1)$.

\section{b) From the assessment/regulation of the internship}

A total of 6 factors were cited solely as barriers by eight studies as follows:

- "the monitoring/supervision of the internship by the perma-

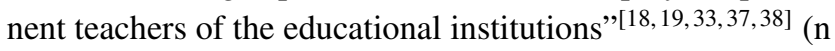
$=5)$;

- The continuous formative assessment of learning by proximity professionals: "the objective observations of trainees' practices"[19,36-38] $(n=4)$, "the formulation of effective feedback meaningful and constructive feedback"[12,33,37,38] ( $\mathrm{n}=$ 4);

- The summative learning assessment: "the use of validated standard supervision and learning tools" $"[19,34](n=2)$, "the direct observation of the trainee's practices" ${ }^{[12]}(\mathrm{n}=1)$ and "the respect of the directives and standards". [18] 


\section{Discussion}

The objective of this review was to report the barriers and facilitators of clinical pedagogical supervision in nursing and obstetrics in sub-Saharan Africa (regardless of the form of supervision: preceptorship, mentorship, or monitoring $)^{[39]}$ and the study population (students, teachers, trainers, clinical staff) and study site (educational institution or health centre). All of the included studies considered factors related to clinical supervision's structure and/or process. Most of the factors reported are at the process level and, more specifically, related to the internship's conduct (clinical teaching and internship evaluation/regulation). Overall, fewer studies have examined the instruments for regulating the relationship between educational institutions and clinical internship sites. However, the factors studied were predominantly cited as barriers in all studies.

We have classified the factors according to the domains (structure and process) based on the Donabedian. ${ }^{[40]}$ The different studies included approached these areas from several angles, reflecting the diversity of factors and the conceptualization of each study. ${ }^{[1,27,30,41,42]}$ However, it is important to specify that the factors are not exclusive but influence each other. ${ }^{[21,37]}$ Overall, our results are similar to those reported in the literature. Barrier and/or facilitating factors are grouped into the structure and process levels.

The discussion is made according to factors level, modality taken according to the results of the present study (barriers/weakness and or facilitator/strongness), the relationship with the results of other studies and the implication of the results in the effectiveness of the clinical pedagogical supervision.

\subsection{Structure level}

\subsubsection{Instruments for regulating the internship}

The instruments for regulating the internship were cited as barriers. This is also signified in other studies by the lack of clarification of the role of supervisors, ${ }^{[27]}$ lack of standards of competence and/or supervision. ${ }^{[16]}$ This state of affairs is not conducive to good regulation of the internship: the instruments of regulation as the principal determinants of the quality of an internship. ${ }^{[43]}$

\subsubsection{Materials (equipment and instruments) and infras- tructure for clinical supervision}

The studies that have examined this factor have all defined it as an obstacle. The literature relates cases of poor working conditions (obsolescence, inadequacy or lack of care equipment), which do not allow for the continuity of techniques according to the standards ${ }^{[20]}$ and lack the necessary materials for the organization of learning situations for the benefit of interns. ${ }^{[14,20,25,26,44,45]}$ However, in contrast to our results concerning infrastructure, Sundler ${ }^{[9]}$ evoked positive experiences with nursing rooms.

\subsubsection{Supervision staff and students}

Almost all of the included studies examined this factor. This might be justified because the methodologies used in most studies conducted to evaluate teaching in clinical settings focus on teacher-student interactions. ${ }^{[46]}$ Similar to this study results, the literature has pointed to a deficit of clinical staff, ${ }^{[20,21,25,44]}$ lack of clarity in the definition of the internship tutor role. ${ }^{[27]}$ Other studies reported clinical staff without basic skills ${ }^{[47,48]}$ and a lack of teachers in quantity and quality. ${ }^{[49]}$ Elsewhere it is reported that there is a satisfactory availability of staff and or clinical instructors. ${ }^{[26,27]}$

\subsubsection{The availability of clinical cases at the internship sites}

This factor was rarely cited but mentioned as a barrier and a facilitator. The lack of clinical cases could be explained by the high number of students at the internship sites and vice versa. ${ }^{[20,25,26,44]}$ The availability of cases for field placement is related to the degree to which the criteria for student selection and assignment to internship sites are met.

In sum, in the structural area of clinical pedagogical supervision, the results of this review indicate that there are more barriers than facilitators. The literature also illustrates this situation. In general, few structures are well organized to support trainees in achieving their goals. ${ }^{[20,45]}$ The 2014 state of the world's midwifery attests to widespread gaps in infrastructure, resources, and capacity that affect midwifery education quality. ${ }^{[49]}$ Data on the midwifery workforce and services in 18 francophone countries in sub-Saharan Africa reveal a lack of equipment and qualified teachers. ${ }^{[49]}$

Thus, in sub-Saharan Africa, the environment in which nurses learn clinical practice faces a multitude of factors that can impede learning. This situation (lack of ability to control conditions in clinical internships) is not conducive to students acquiring the expected skills (learning objectives). ${ }^{[50]}$ However, the differences in data can be attributed to differences in cultural, socio-economic and political factors related to each structure. ${ }^{[22]}$

\subsection{Process level}

\subsubsection{Preparation of the clinical internship}

Similar results to those in this review are reported in the literature.

There are difficulties in carrying out the clique simulations. The relative reasons are the number of students, the lack of practice hours, the lack of auditoriums (professors), the lack of learning materials, the trainers' low skills, and the 
lack of knowledge of the internship objectives. ${ }^{[16,17,20,25,27]}$ From communication between internship sites and educational institutions, clinical supervisors are often not informed of students' arrival on the internship site. ${ }^{[14,19,24,52]}$ The student's insufficient preparation by his lack of mastery of the theoretical aspects of the practice is also highlighted. ${ }^{[52,53]}$ In this regard, Kabwe et al. ${ }^{[20]}$ speak of a lack of prerequisites. However, the internship and practical learning require serious preparation for both the teacher (information and educational aspects of supervision) and the student. The student must have the scientific, technical and relational knowledge required to face the realities of the hospital environment. This will allow him to do a more efficient and safer work for the patient under his care. ${ }^{[6]}$

\subsubsection{Reception and integration of interns in the clinical environment}

Studies have also reported the poor quality of student reception upon arrival at the internship. A study conducted in Benin, Otti et al. ${ }^{[2]}$ reported that most students affirmed that they did not benefit from a visit to the office buildings on the first day of the internship, nor were they introduced to the internship supervisors. In addition, they stated that they did not receive a welcome interview on the practical details of the internship, nor the organization of the department and its mode of operation. Also, no information was provided to them by the internship supervisors, neither on the department's material resources nor on their learning resources during the internship. Gemuhay et al. ${ }^{[25]}$ reported a lack of pre-clinical orientation, distribution and clarification of clinical learning objectives to students.

\subsubsection{The course of the internship}

Research has also identified barriers and/or facilitators to clinical teaching and internship assessment.

\section{1) Clinical teaching}

a) Of the development of clinical teaching skills by supervisors

Kaphagawani and Useh ${ }^{[22]}$ made a case for contradictory practices between the taught nursing ideal and the clinical environment. Other authors have noted that students were faced with a range of issues that affect their performance, such as maintaining good relationships with clinical staff and instructors, ${ }^{[23,25,54]}$ negative critics ${ }^{[25]}$ and the bad leadership style of the internship supervisor or care manager. ${ }^{[2]}$ Similarly, Memarian et al. ${ }^{[55]}$ described a learning environment characterized by unsupportive interpersonal communication, lack of access to direct experience, traditional clinical behaviourism, and a stressful psychosocial environment. Elsewhere, these aspects of supervision's development of clinical teaching skills were also often reported as facilitators. ${ }^{[1,2,9,14,27]}$ One

Published by Sciedu Press of the reasons for this dual situation might be that it is influenced by the state of the teacher's (supervisor's) personal and professional values (caring) and the notion of the teacher's professional identity in the teaching environment. ${ }^{[47]}$

\section{b) About student behavior}

The literature has also identified barriers to the effectiveness of clinical pedagogical supervision. In this regard, Kabwe et al. ${ }^{[20]}$ reported a lack of questioning, indifference to learning the job, indiscipline, and absences from the internship by students. In addition, inability to demonstrate knowledge and skills, attitude problems, unprofessional and unfriendly behavior with clinical instructors, overconfidence, and lack of motivation to learn or work, Luhanga et al. ${ }^{[53]}$ previously reported lack of trust dishonesty. Thus, students' behavior in clinical practice can positively or negatively impact their learning. ${ }^{[22]}$ Indeed, the quality of the teacher's relationship with the students influences the transmission of theoretical knowledge to practical knowledge and the evaluation of the students' needs and clinical competence. ${ }^{[46]}$

\section{2) Evaluation and regulation of the internship}

The methods and procedures for evaluating the internship are inadequate. ${ }^{[51]}$ Indeed, using non-standardized forms without creating learning situations for the students and depending on the instructor's (coach's) taste is the important aspect that the students mentioned as obstacles to their learning in the study of Memarian et al. ${ }^{[5]}$ In addition, assessment of clinical learning is a significant challenge for the teacher. ${ }^{[6]}$

In summary, the clinical pedagogical supervision process as a whole is deficient. This is related to poor working conditions that do not allow for continuity of techniques according to standards ${ }^{[20]}$ and affect the supervision actors' abilities and motivation. ${ }^{[45]}$ This is not favorable for students to acquire the expected skills. ${ }^{[50]}$

\subsection{Limitations of the study}

Indeed, despite applying a comprehensive search strategy, we are not sure that all relevant studies were retrieved and included in this review. Therefore, not all databases were searched, and no further contact with an author was made. In addition, important sources of information on clinical educational supervision in nursing and obstetrics may exist and are inaccessible because they have not been published in the websites consulted or encoded in the databases used. Finally, as only nine primary research studies were included, it is impossible to draw adequate conclusions based on the limited amount and quality of evidence available.

\subsection{Recommendations for practice}

The results of this systematic review point to some implications. The absence of instruments to regulate the internship 
leads to a lack of clarity in the role of supervisors. This situation could lead to the non-performance of some clerkship activities, which would not be conducive to achieving clerkship objectives. In addition, the lack of clinical staff would reduce the likelihood that students would receive support from clinical supervisors. Thus, students may not acquire some skills, which may be felt in their careers. In addition, failure to acquire certain skills related to the lack of clinical cases would render students, at the end of the training, incompetent in the management of cases not encountered during their practicum.

In light of the above implications in particular, and in general, all of the weaknesses in clinical pedagogical supervision identified by the study, it is important to develop strategies to improve the latter's effectiveness. To this end:

The central authorities (ministries in charge of health and education) must promote clinical pedagogical supervision's institutionalization (formalization). This will contribute, among other things, to the availability, security and motivation of the actors, particularly the internship supervisors.

Nursing and midwifery student educational institutions, in collaboration with health care centers, should: a) elaborate structured educational programs that highlight the characteristics (skills and profiles) of the supervisors, the characteristics of the internship sites, the expected skills of the interns, and the teaching and learning strategies, b) elaborate and disseminate all the instruments for regulating internships, for rational management of clinical supervision, c) improve the reception capacities of the internship sites (equipment, clinical staff, materials, tools, activity packet, etc.) to promote learning opportunities, d) train and supervise the interns, and e) provide them with the necessary tools for their training to promote learning opportunities, e) train and supervise internship supervisors on clinical pedagogical supervision.

Nursing and midwifery student educational institutions must first ensure good preparation for the internship by a) promoting clinical simulations by developing high-fidelity laboratories to prepare and facilitate direct learning in the internship and to respond to the lack of clinical cases due to the high number of interns, b) respecting criteria for internship site selection and assignment of interns, c) preparing student interns (psychological, materials, tools, internship preparation meeting, etc.), d) effective communication with internship sites, e) the respect of the criteria for the selection of internship sites and the assignment of interns. Secondly, they must ensure that supervision runs smoothly through: a) promoting the appropriate application of the competency-based approach as an appropriate teaching/learning and evaluation strategy in clinical internships, b) supervising the interns.

\section{Conclusion}

This study identified and described 65 factors of clinical pedagogical supervision, the subjects of 9 studies conducted in sub-Saharan Africa from January 2011 to December 2020. Most (60) of the factors were cited as barriers and only 11 facilitators. These factors were structural (related to infrastructure, materials, instruments, and personnel) and procedural (preparation of supervision, reception of trainees, and clinical teaching and learning assessment).

This systematic review is thus of great interest because it provides a complete overview (at the structural and process levels) of the barriers and facilitators to effective clinical pedagogical supervision in sub-Saharan Africa. In addition, it will help readers (supervisors, students, and decision-makers) be aware of student supervision challenges.

However, clinical learning environments are unique and can be attributed to the different cultural, socioeconomic, and political factors, in addition to the curriculum and organization of clinical nursing and obstetric education. Consequently, research needs to be conducted to explore clinical supervision of students at the country level and or across cultures in different countries.

\section{CONFlicts OF INTEREST Disclosure}

The authors declare that they have no financial or personal relationship(s) that may have inappropriately influenced them in writing this article.

\section{REFERENCES}

[1] Khan A, Begum H, Rehman AU, et al. Experiences of healthcare students and the challenges posed by their clinical learning environment. Cent Eur J Nurs Midwifery. 2020; 11(1): 19-24. https://doi.org/10.15452/cejnm.2020.11.0004

[2] Makhlof EHA, El-Saman SE-SA-Motaleb. Internship Nurses' Satisfaction with Clinical Learning Environment in Intensive Care Unit. IOSR J Nurs Health Sci. 2017; 06(02): 112-119. https : //doi.org/10.9790/1959-060205112119

[3] Papastavrou E. Nursing students' satisfaction of the clinical learning environment: a research study. BMC Nurs. 2016; 10. PMid:27436992 https ://doi.org/10.1186/s12912-016-0164-4

[4] Papastavrou E, Lambrinou E, Tsangari H, et al. Student nurses experience of learning in the clinical environment. Nurse Educ Pract. 2010; 10(3): 176-182. PMid:19700368 https://doi.org/10.1 016/j.nepr.2009.07.003 
[5] AlHaqwi AI, Taha WS. Promoting excellence in teaching and learning in clinical education. J Taibah Univ Med Sci. 2015; 10(1): 97-101. https://doi.org/10.1016/j.jtumed.2015.02.005

[6] Phaneuf M. L'apprentissage/enseignement en milieu clinique. 2012. Available from: http://www.prendresoin.org/wp-content /uploads/2013/01/Apprentissage-enseignement_cliniq ue.pdf Accessed 12 June 2019.

[7] Benoît R, Caroline V, Louise V. Accompagner des étudiants: Quels rôles pour l'enseignant? Quels dispositifs? Quelles mises en oeuvre? 1st ed. 2010. De Boeck https://books.google.bf/books/ab out/Accompagner_des_\%C3\%A9tudiants .html?id=PHhr1X0 GGoAC\&printsec $=$ frontcover\&source $=$ kp_read_button\&r edir_esc=y\#v=onepage\&q\&f=false Accessed 26 June 2021.

[8] Boru JJ. Du tuteur a la fonction tutorale: contradictions et difficultés de mise en œuvre. Rech Form. 1996; 22(1): 99-114. https: //doi.org/10.3406/refor.1996.1349

[9] Sundler AJ, Björk M, Bisholt B, et al. Student nurses' experiences of the clinical learning environment in relation to the organization of supervision: A questionnaire survey. Nurse Educ Today. 2014; 34(4): 661-666. PMid:23850574 https://doi.org/10.1016/j. nedt.2013.06.023

[10] De Witte N, Labeau S, De Keyzer W. The clinical learning environment and supervision instrument (CLES): Validity and reliability of the Dutch version (CLES+NL). Int J Nurs Stud. 2011; 48(5): 568572. PMid:20947082 https://doi.org/10.1016/j.ijnurstu .2010 .09 .009

[11] Flott EA, Linden L. The clinical learning environment in nursing education: a concept analysis. J Adv Nurs. 2016; 72(3): 501-513. PMid:26648579 https ://doi.org/10.1111/jan.12861

[12] Otti A, Pirson M, Piette D. Perception de la gestion et de la qualité de l'encadrement pédagogique clinique en sciences infirmières et obstétricales par des étudiants béninois de l'INMeS, une étude descriptive transversale quantitative et qualitative. Rev Francoph Int Rech Infirm. 2015; 1(3): 169-178. https://doi .org/10.1016/j. refiri.2015.06.001

[13] World Health Organization. WHO recommendations for clinical mentoring to support scale-up of HIV care, antiretroviral therapy and prevention in resource-constrained settings. 2006. Geneva. World Health Organization. Available from: http://www.who.int/hiv/pub/ guidelines/clinicalmentoring.pdf Accessed June 272021.

[14] Kaki MK, Imvar EK, Mudisu LK, et al. Perception des étudiants infirmiers face à leurs encadreurs de stage: Cas des stagiaires evoluant aux Cliniques Universitaires de Lubumbashi. Rev L'Infirmier Congo. 2018; 45-49.

[15] Najafi Kalyani M, Jamshidi N, Molazem Z, et al. How do nursing students experience the clinical learning environment and respond to their experiences? A qualitative study. BMJ Open. 2019; 9(7): e028052. PMid:31350243 https://doi.org/10.1136/bmjope $\mathrm{n}-2018-028052$

[16] Bharj KK, Embo M. Factors affecting quality of midwifery students learning in the workplace: Results of two ICM congress workshops. Midwifery. 2018; 62: 116-118. PMid:29674174 https : //doi.org/10.1016/j.midw.2018.03.018

[17] Catherine VN, Stéphane C. Une recherche collaborative autour des difficultésdes maîtres de stage à accompagner leur stagiaire. 2013; 21.

[18] Mbakaya BC, Kalembo FW, Zgambo M, et al. Nursing and midwifery students' experiences and perception of their clinical learning environment in Malawi: a mixed-method study. BMC Nurs. 2020; 19(1): N.PAG-N.PAG. PMid:32943984 https://doi.org/10.1 186/s12912-020-00480-4

Published by Sciedu Press
[19] Otti A, Pirson M, Piette D. Perception des encadrants de stage du processus de gestion et de la qualité de l'encadrement pédagogique clinique en sciences infirmières et obstétricales au bénin. Rech Soins Infirm. 2015; (123): 77-88. https://doi.org/10.3917/rsi.123.0077

[20] Kabwe M, Chuy K, Kankolongo C, et al. Perception des formateurs et des encadreurs de stage concernant le processus d'enseignementapprentissage et le développement des compétences professionnelles des étudiants: IOSR-JNHS. 2020; 9: 39-49.

[21] Kabwe M, Chuy K, Odia M, et al. Perception affective des apprenants et des bénéficiaires de leurs soins enstage sur leprocessus d'enseignement-apprentissage à l'Institut Supérieur des Techniques Médicales de Lubumbashi, République Démocratique du Congo. IOSR J Nurs Health Sci. 2021; 10(1): 11-17.

[22] Kaphagawani NC, Useh U. Analysis of Nursing Students Learning Experiences in Clinical Practice: Literature Review. Stud Ethno-Med. 2013; 7(3): 181-185. https://doi.org/10.1080/09735070.2 013.11886459

[23] Mohamed F. Assiut Internship Nursing Students' Opinions of Factors Affecting Their Clinical Learning Environment. Assiut Sci Nurs J. 2016; 4(8): 182-187. https://doi.org/10.21608/asnj. 2016 .60401

[24] Otti A, Pirson M, Piette D, Coppieters T Wallant Y. Analyse d'interventions pour améliorer l'encadrement clinique des étudiants infirmiers au Bénin. Sante Publique Vandoeuvre-Nancy Fr. 2017; 29(5): 731-739. PMid:29384307 https://doi .org/10.3917/sp ub. 175.0731

[25] Gemuhay HM, Kalolo A, Mirisho R, Chipwaza B, Nyangena E. Factors Affecting Performance in Clinical Practice among Preservice Diploma Nursing Students in Northern Tanzania. Nurs Res Pract. 2019; 2019: 1-9. PMid:30941212 https://doi.org/10.1155/ 2019/3453085

[26] Kaliyangile B. Factors Influencing Student Nurses' Clinical Learning during their Clinical Practice at Rusangu University, Monze campus, Zambia. TEXILA Int J Nurs. 2020; 6(1): 28-37. https: //doi.org/10.21522/TIJNR.2015.06.01.Art003

[27] Vizcaya-Moreno MF, Pérez-Cañaveras RM, Jiménez-Ruiz I, et al. Student nurse perceptions of supervision and clinical learning environment: a phenomenological research study. Enferm Glob. 2018; 17(3): 306. https://doi .org/10.6018/eglobal.17.3.27610 1

[28] DRASS-PACA D. Evaluation de la qualité de la formation en stage à destination des étudiants paramédicaux. 2008. Available from: https://docplayer.fr/566702-Evaluation-d e-la-qualite-de-la-formation-en-stage.html Accessed 25 September 2021.

[29] Donabedian A. The definition of quality and approaches to its assessment. 1980. Ann Arbor, Mich. Health Administration Press.

[30] Otti A, Magali P, Johanne G, et al. Un outil d'analyse de la qualité de la supervision clinique en sciences infirmières. L'infirmière Clin. 2017; 14(1): 15.

[31] Michel G. Traduction francaise des lignes directrices PRISMA pour l'écriture et la lecture des revues systématiques et des méta-analyses. 15157 Kinesither Rev. 2015.

[32] Hong QN, Fàbregues S, Bartlett G, et al. Mixed Methods Appraisal Tool (MMAT), version 2018. Registration of Copyright (\#1148552), Canadian Intellectual Property Office, Industry Canada. 2018; 6.

[33] Kamphinda S, Chilemba EB. Clinical supervision and support: Perspectives of undergraduate nursing students on their clinical learning environment in Malawi. Curationis. 2019; 42(1): e1-e10. PMid:31170797 https://doi.org/10.4102/curationis.v42 i1. 1812 
[34] Vuso Z, James S. Effects of limited midwifery clinical education and practice standardisation of student preparedness. Nurse Educ Today. 2017; 55: 134-139. PMid:28595070 https://doi.org/10.1016/ j.nedt. 2017.05 .014

[35] Eta VEA, Atanga MBS, Atashili J, D’Cruz G. Nurses and challenges faced as clinical educators: a survey of a group of nurses in Cameroon. Pan Afr Med J. 2011; 8: 28. PMid:22121437 https: //doi.org/10.4314/pamj.v8i1.71085

[36] Rikhotso SR, Williams MJS, de Wet G. Student nurses' perceptions of guidance and support in rural hospitals. Curationis. 2014; 37(1): e1-e6. https://doi.org/10.4102/curationis.v37i1.1164

[37] Kaphagawani NC, Useh U. Clinical Supervision and Support: Exploring Pre-registration Nursing Students' Clinical Practice in Malawi. Ann Glob Health. 2018; 84(1): 100-109. PMid:30873795 https : //doi.org/10.29024/aogh.16

[38] Mubeezi MP, Gidman J. Mentoring student nurses in Uganda: A phenomenological study of mentors' perceptions of their own knowledge and skills. Nurse Educ Pract. 2017; 26: 96-101. PMid:28787631 https://doi.org/10.1016/j.nepr.2017.07.010

[39] St-Pierre L. Se former pour mieux superviser en sciences infirmières. 2007. Montréal. Beauchemin. Available from: www. cheneliere.c a/260-livre-se-former-pour-mieux-superviser-en-sci ences-infirmieres.html?siteComplet=1 Accessed 12 July 2021.

[40] Donabedian A. Evaluating the Quality of Medical Care: Evaluating the Quality of Medical Care. Milbank Q. 2005; 83(4): 691-729. PMid:16279964 https://doi.org/10.1111/j.1468-0009.20 $05.00397 . \mathrm{x}$

[41] Dunn SV, Hansford B. Undergraduate nursing students' perceptions of their clinical learning environment. J Adv Nurs. 1997; 25(6): 1299 1306. PMid:9181430 https ://doi.org/10.1046/j.1365-264 8.1997.19970251299.x

[42] Fraser BJ. Science Learning Environments: Assessment, Effects and Determinants. In: Fraser BJ, Tobin KG, editors. International Handbook of Science Education. Dordrecht. Springer Netherlands. 1998; 527-561. https://doi.org/10.1007/978-94-011-4940-2_3 1

[43] Cremonini V, Ferri P, Artioli G, et al. Nursing students' experiences of and satisfaction with the clinical learning environment: the role of educational models in the simulation laboratory and in clinical practice. Acta Biomed Ateneo Parmense. 2015; 86: 194-204.

[44] Pinehas LN, Mulenga E, Amadhila J. Factors that hinder the academic performance of the nursing students who registered as first years in 2010 at the University of Namibia (UNAM), Oshakati
Campus in Oshana, Namibia. J Nurs Educ Pract. 2017; 7(8): 63. https://doi.org/10.5430/jnep.v7n8p63

[45] Wilkins AM, Ellis G. Enhancing learning environments by maximising support to mentors. 2004. Available from:

[46] Pharand D. L'evaluation de l'enseignement des sciences infirmieres en milieu clinique: des competences a developper, plutot que des comportements a prioriser. Rev Sci Leducation. 2007; 33(3): 703725. https://doi.org/10.7202/018965ar

[47] Kinnevey C. Addressing Obstetrical Challenges at 12 Rural Ugandan Health Facilities: Findings from an International Ultrasound and Skills Development Training for Midwives in Uganda. Int J MCH AIDS IJMA. 2016; 5(1). PMid:28058192 https ://doi .org/10.2 1106/ijma. 106

[48] Knight HE, Self A, Kennedy SH. Why Are Women Dying When They Reach Hospital on Time? A Systematic Review of the ‘Third Delay'. PLoS ONE. 2013; 8(5): e63846. PMid:23704943 https ://doi.org/10.1371/journal.pone.0063846

[49] UNFPA. L'État de la pratique de sage-femme dans le monde 2014. UNFPA. 2014. New York. Available from: https : //www . unfpa.org/fr/publications/1\%C3\%A9tat -de-la-pratique-de-sage-femme-dans-le-monde-2014 Accessed 18 August 2021.

[50] Terzioğlu F, Yücel Ç, Koç G, et al. A new strategy in nursing education: From hybrid simulation to clinical practice. Nurse Educ Today. 2016; 39: 104-108. PMid:27006040 https ://doi.org/10.1016/ j.nedt. 2016.01 .009

[51] Hakim A. Nursing students' satisfaction about their field of study. J Adv Med Educ Prof. 2014; 2(2): 6.

[52] Lakrami F, Labouidya O, Elkamoun N. Pedagogie universitaire et classe inversee: vers un apprentissage fructueux en travaux pratiques. Rev Int Pedagogie L'enseignement Supér. 2018; 34(3). https://doi.org/10.4000/ripes.1793

[53] Luhanga F, Yonge O, Myrick F. Precepting an unsafe student: The role of the faculty. Nurse Educ Today. 2008; 28(2): 227-231. PMid:17553601 https://doi.org/10.1016/j.nedt.2007.04 .001

[54] Chan CKL, So WKW, Fong DYT. Hong Kong Baccalaureate Nursing Students' Stress and Their Coping Strategies in Clinical Practice. J Prof Nurs. 2009; 25(5): 307-313. PMid:19751936 https : //doi.org/10.1016/j.profnurs.2009.01.018

[55] Memarian R, Vanaki Z, Baraz S. Learning challenges of nursing students in clinical environments: A qualitative study in Iran. J Educ Health Promot. 2015; 4(1): 52. PMid:26430679 https : //doi.org/10.4103/2277-9531.162345 